\title{
Fatty acid composition of sprat (Sprattus sprattus) and herring (Clupea harengus) in the Baltic Sea as potential prey for salmon (Salmo salar)
}

\author{
Marja Keinänen ${ }^{1}$, Reijo Käkelä ${ }^{2}$, Tiina Ritvanen ${ }^{3}$, Timo Myllylä ${ }^{4}$ Jukka Pönni ${ }^{1}$ and Pekka J. Vuorinen ${ }^{1 *}$ (D)
}

\begin{abstract}
Sprat (Sprattus sprattus) and small herring (Clupea harengus) are the dominant prey fish of Atlantic salmon (Salmo salar) in the Baltic Sea. If the fatty acid (FA) proportions of sprat and herring differ, the dietary history of ascending salmon could be determined from their FA profiles. Therefore, we investigated the FA composition of several age groups of whole sprat and small herring, caught from the three main feeding areas of salmon in autumn and spring. Oleic acid (18:1n-9) was the most prevalent FA in sprat and characteristic of this species. In herring, palmitic acid (16:0) was the most common FA, but herring lipid was characterized by $n-6$ polyunsaturated FAs, and moreover, by palmitoleic acid (16:1n-7) and vaccenic acid (18:1n-7). Due to the higher lipid content of sprat, the concentrations of all other FAs, excluding these, were higher in sprat than in herring. The concentration of docosahexaenoic acid (DHA, 22:6n-3) increased with an increase in the lipid content and was consequently highest in the youngest specimens, being in young sprat almost double that of young herring, and 2.6 times higher in the sprat biomass than in that of herring. As a result of a decrease in the DHA concentration with age, the ratio thiamine/DHA increased with respect to age in both species, and was lower in sprat than in herring. It is concluded that an abundance of DHA in the diet of salmon most likely increases oxidative stress because of the susceptibility of DHA to peroxidation, and thus decreases thiamine resources of fasting, prespawning salmon. Because the FA composition of sprat and herring differs, and the relative abundancies of prey fish differ between the feeding areas of salmon, the feeding area of ascending salmon can most probably be derived by comparing their FA profiles.
\end{abstract}

Keywords: Atlantic salmon Salmo salar, Baltic Sea, Fatty acid, Herring Clupea harengus, Lipid, M74 syndrome, PUFA, Sprat Sprattus sprattus, Thiamine deficiency

\section{Background}

Polyunsaturated fatty acids (PUFAs) of the $n-3$ family, docosahexaenoic acid (DHA, 22:6n-3) and eicosapentaenoic acid (EPA, 20:5n-3), are important components of cell membranes, also being precursors of bioactive molecules, and provide a source of energy in vertebrates $[1,2]$. An adequate supply of DHA is important for the optimal development and functioning of the nervous

\footnotetext{
*Correspondence: pekka.vuorinen@luke.fi

${ }^{1}$ Natural Resources Institute Finland (Luke), Management and Production

of Renewable Resources, P.O. Box 2, FI-00791 Helsinki, Finland

Full list of author information is available at the end of the article
}

system [3,4]. Arachidonic acid (ARA, 20:4n-6), of the n-6 family, is also considered as an essential PUFA [1]. However, because of their high number of double bonds, highly unsaturated fatty acids ( $n-3$ HUFAs) are extremely prone to lipid peroxidation, especially in the absence of sufficient antioxidant protection [5-7]. Monounsaturated fatty acid (MUFA), oleic acid (18:1n-9), also increase the vulnerability of fish to oxidative stress through free radical oxidation of lipids [8]. Thiamine (vitamin B1) acts as a coenzyme for the key enzymes of energy metabolism, thus having a direct linkage to fatty acid (FA) metabolism, and also functions as an antioxidant $[8,9]$. In radical 
chain reactions with several other antioxidants and other compounds, thiamine is irreversibly transformed into inactive forms $[8,9]$.

Diet-related thiamine deficiency of the Atlantic salmon (Salmo salar) feeding in the Baltic Sea is known as the M74 syndrome [10]. M74 manifests as mortalities of yolk-sac fry (i.e., an eleutheroembryo or free embryo [11]), with mortality increasing when the thiamine concentration in salmon eggs is very low [12, 13]. When studying the antioxidants of salmon eggs and yolk-sac fry in connection with M74, Lundström et al. [14] concluded that peroxidation mechanisms were involved in thiamine deficiency. Moreover, Pickova et al. [15] found an imbalance between the oxidative potential and antioxidant capacity in the eggs of salmon whose offspring suffered from M74. The M74 syndrome has been linked to a large food biomass and an abundance of sprat (Sprattus sprattus) in the Baltic Proper (BPr) [16, 17]. According to Keinänen et al. [18], a high lipid content in the prey fish biomass of salmon and an abundant supply of lipid-rich food explains the incidence of thiamine deficiency.

The two main prey species of salmon in the Baltic Sea are the sprat and herring (Clupea harengus), constituting approximately $90 \%$ of the salmon diet [19]. The abundance of these prey species varies between the main feeding areas of salmon, the BPr, the Bothnian Sea (BS) and the Gulf of Finland (GoF) (Fig. 1). Accordingly, the proportions of sprat and herring vary in the salmon diet [19-21], since salmon apparently prey on the most available species of an appropriate size. The BPr is the main spawning ground of sprat $[22,23]$. There, the proportions of sprat and herring have mainly varied as a consequence of large changes in the size of the sprat stock. Sprat has been the most prevalent species in the BPr since the end of the 1980s, i.e., after the collapse of the stock of cod (Gadus morhua), which is its main predator [17, 24].

Most wild salmon feeding in the Baltic Sea originate from the rivers running into the northern part of the Gulf of Bothnia and largely migrate to feed in the BPr. However, some of them halt their feeding migration in the southern part of the Gulf of Bothnia, the BS [23, 25], where herring comprise almost the exclusive prey fish of salmon $[17,19,20]$. Sprat do not reproduce in the BS due to the low salinity [23]. Following the explosive growth of the Baltic sprat stock in the early 1990s, some sprat have annually dispersed to the BS from more southern parts of the Baltic Sea $[19,20]$, but the proportion of sprat in the salmon prey biomass in the BS has remained $<5-10 \%$ [17]. In the GoF, sprat might have been more abundant than herring from the years of strong sprat recruitment onwards, although herring was previously the dominant prey species of salmon in the area $[26,27]$.

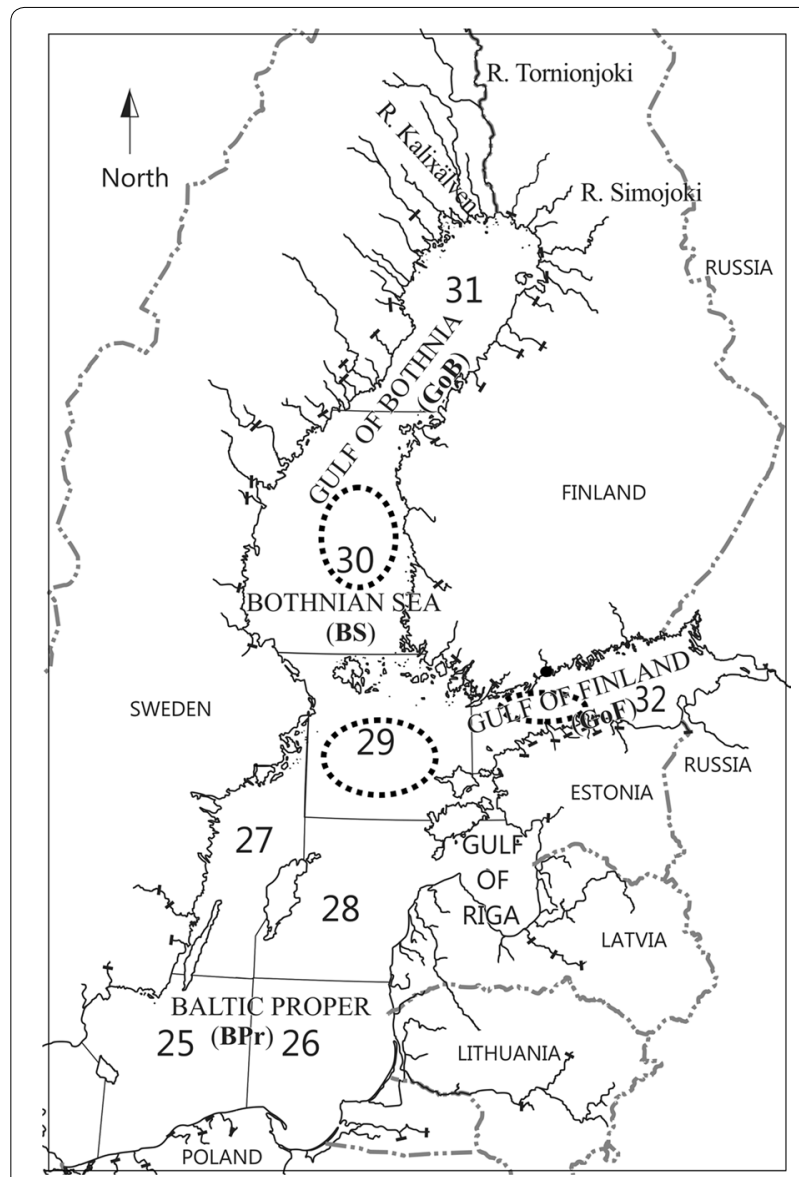

Fig. 1 Sampling locations (ellipses) in the Baltic Sea with the statistical subdivisions (SDs) of the International Council for the Exploration of the Sea (ICES) in the Baltic Proper (BPr, SD25-29), Bothnian Sea (BS, SD30) and Gulf of Finland (GoF, SD32)

At the beginning of the 1990s, M74 mortalities among salmon stocks of the northern Gulf of Bothnia rivers, such as the Rivers Tornionjoki and Simojoki, even exceeded $80 \%[28,29]$. Thereafter, the incidence of thiamine deficiency has decreased concurrently with some strengthening of the cod stock and the decrease in the sprat stock [30]. However, the egg thiamine concentration and M74 mortality have also greatly varied within years among individual salmon of each river. We do not know whether this variation is dependent on the feeding preferences of individual salmon or is related to the feeding area. It would be possible to resolve this if we knew the FA composition of prey fish, because the dietary FA composition is reflected in the FA composition of salmon [31-33]. The proportions of FAs can be used in signature analysis to assess prey and predator relationships [34]. Thus, it is most important to determine how the FA compositions of sprat and herring differ, and whether the FA compositions differ between the feeding areas of salmon. 
According to Røjbek et al. [35], sprat lipid is characterized by large proportions of MUFAs, whereas the proportions of PUFAs are higher in the whole body lipid of herring than in sprat. In the few other studies on the FA composition of Baltic herring [36-38] and sprat [39], FAs have been analysed in fillets. However, the lipid content of fillets and whole fish may differ, as was found in Norwegian herring [40], and the FA composition of fillets and whole fish probably also differs. Moreover, the FA content has been found to change as a function of weight in herring [38] and in sprat [39]. Even salmon with a total length of $>60 \mathrm{~cm}$ prefer prey fish with a total length of 4-15 cm, and only seldom consume fish with a total length of more than $19 \mathrm{~cm}$ [19]. Thus, all age groups of sprat are appropriate as salmon prey, but in general only young age groups of herring $[17,26]$. Previous studies on the FAs of Baltic herring, including that by Røjbek et al. [35], have not considered whether the analysed fish were of a suitable size to be preyed on by salmon. Thus, it is necessary to examine the FA composition of sprat and those herring that fit into this category.

In this study, we investigated the differences in the FA composition of sprat and those herring that, according to their size, are potential prey of salmon, taking into account spatial and seasonal variation in the FA composition, and the effect of fish age on this variation. Moreover, the variation in the thiamine concentration in relation to the FA content in sprat and herring and in their biomasses was examined. In sprat, and specifically in young sprat, the content of unsaturated FAs is expected to be higher than in herring, but the dominance of MUFAs and DHA and their possible relationships with thiamine also needed to be clarified. Prey fish of an appropriate size for salmon [17] were analysed as whole fish to simulate the salmon diet, similarly to some previous studies on lipid and thiamine contents in sprat and herring [18, 41, 42].

\section{Methods}

\section{Sampling of sprat and herring}

Specimens of sprat and herring were collected from commercial midwater trawl catches from the northern BPr, the BS and the GoF (Fig. 1). Sampling was performed during the last quarter of the year 2003 (late autumn) and the first quarter of the next year (early spring 2004) in connection with sampling for stock assessment in the ICES (International Council for the Exploration of the Sea) Baltic Fisheries Assessment Working Group by the Natural Resources Institute Finland (formerly the Finnish Game and Fisheries Research Institute). The size of the sprat stock had almost halved by these years from the peak values of the 1990s [30, 43], and M74 mortality was negligible during 2003-2005 [30], i.e., among the offspring of salmon that during the feeding migration had fed on clupeids concurrently with the sampling of the present study.

The total length and weight of each sprat and herring were measured and Fulton's condition factor (CF) was calculated as: $\mathrm{CF}=100 \mathrm{WL}^{-3}$, where $\mathrm{W}=$ body weight (g) and $\mathrm{L}=$ total length $(\mathrm{cm})$. Otoliths were removed for age determination, and fish specimens were individually sealed in numbered Minigrip ${ }^{\circledR}$ bags and immediately frozen at $-20{ }^{\circ} \mathrm{C}$. Fish were stored at this temperature for two to three weeks before homogenisation for analysis. The ages of the sprat and herring were determined from thin slices of otoliths that were stained with a modification of the neutral red staining method described by Richter and McDermott [44]. Only those specimens of herring that were of a suitable size to be preyed on by salmon (i.e. total length $<19 \mathrm{~cm}$ ) [17] were included in analysis of FA composition.

After the age determination, the specimens of sprat (327 in autumn and 503 in spring) and herring (971 in autumn and 1311 in spring) were pooled into age groups by area and season. To simulate the actual diet of salmon, herring and sprat individuals were pooled as whole fish. The age groups for each sampling area and season were 1 , $3(2-3)$ and $7(6-8)$ years for sprat and 1, 2, 3 and 6 years for herring, but no 1-year-old sprat were caught from the BS in spring. The total number of sprat and herring pools was therefore 41 . The number of sprat specimens varied from 12 to 92 and those of herring from 7 to 133 in the areal and seasonal age groups or pools (whole body homogenates) for analysis. When examining the age relationships of the FA composition, lipid content and thiamine concentration, the age group 10 of herring $(\mathrm{N}=168,2-61$ per pool) was additionally taken into account in the statistical analyses.

Partially thawed fish pools were homogenised with equipment using cutting blades (Waring Laboratory Blender) at a temperature of $+4{ }^{\circ} \mathrm{C}$. Two to eight fish specimens were homogenized at a time and all the subhomogenates within a pool were combined and thoroughly mixed. After homogenization of all specimens within each of the pools, the equipment was thoroughly washed and rinsed with purified ethanol $(\geq 94 \%)$. The efficiency of this homogenisation procedure was satisfactory, as demonstrated in an earlier study that reported concentrations of environmental toxicants of these herring and sprat homogenates/pools [42]. Homogenates were sampled for the analysis of FAs (20 g) and thiamine (5 g), with the subsamples being stored at $-80{ }^{\circ} \mathrm{C}$ for four to six weeks prior to analysis.

\section{Biochemical analyses \\ Lipids}

The total lipid content of whole body homogenates of sprat and herring was derived from the procedure for 
the analysis of organohalogen concentrations [42] at the National Institute for Health and Welfare. Briefly, subsamples of homogenates (ca. $100 \mathrm{~g}$ ) were freeze-dried before Soxhlet extraction for $20 \mathrm{~h}$ with toluene, and the lipid content was measured gravimetrically (Sartorius BP210 with the precision of $0.6 \mathrm{mg}$ ) from the extract [45].

\section{Fatty acids}

For FA analysis, lipids of sprat and herring homogenates were extracted using the Schmid-Bondzynski-Ratzlaff method [46]. Thus, each sample was first digested with hydrochloric acid. After ethanol addition, lipid was extracted with diethyl ether and light petroleum. Finally, solvents were removed by evaporation. The difference between the total lipid determination with Soxhlet extraction and the Schmid-Bondzynski-Ratzlaff method in sprat and herring homogenates was tested by linear regression. The two methods gave similar results: $\mathrm{y}=1.01 \mathrm{x}-0.54, R^{2}=0.982, p<0.001, \mathrm{~N}=22$.

The extracted lipid fraction was saponified, followed by liberation and esterification of FAs using methanol in the presence of boron trifluoride [47]. The produced FA methyl esters (FAMEs) were analysed by gas-liquid chromatography (Agilent HP 5890), employing a HP Innowax capillary column $(30 \mathrm{~m}, 0.32 \mathrm{~mm} \times 0.5 \mu \mathrm{m})$ and flame-ionization detection. The GC parameters were as follows: carrier gas He with flow $1.1 \mathrm{ml} \mathrm{min}^{-1}$; splitless injection volume $1 \mu \mathrm{l}$; injector temperature $240{ }^{\circ} \mathrm{C}$; initial oven temperature $70{ }^{\circ} \mathrm{C}$, held for 2 min, then increased by $15{ }^{\circ} \mathrm{C} \mathrm{min}{ }^{-1}$ to $200{ }^{\circ} \mathrm{C}$ and $7{ }^{\circ} \mathrm{C} \mathrm{min}{ }^{-1}$ to $230{ }^{\circ} \mathrm{C}$, and held at $230{ }^{\circ} \mathrm{C}$ for $25 \mathrm{~min}$; detector temperature $300{ }^{\circ} \mathrm{C}$. Individual FAMEs were identified on the basis of relative retention times compared to FAME standard mixtures (Nu-Chek-Prep, Inc. USA: 403, 08b, 17aa, 458, 461, 68d and Larodan Sweden: Qualmix Fish S). FAs were derived based on their FAME peak area as a proportion of the total area of all the integrated chromatographic peaks. To approximate the supply of FAs to salmon from the prey fish, FAs of sprat and herring are reported as lipidweighted proportions (hereafter concentrations), which were calculated by multiplying the FAME proportions by the lipid content $\left(\mathrm{mg} \mathrm{g}^{-1}\right)$ of the sample tissue.

FAs were summed into categories based on the degree of their saturation, i.e., the number of double bonds. Thus, SFAs include all the saturated FAs, MUFAs all the monounsaturated FAs, and PUFAs all the polyunsaturated FAs, i.e., those containing from two to six double bonds. The PUFAs were also classified into $n-3$ and $n-6$ families [48]. Among $n$-3 HUFAs, we included those $n$ 3 PUFAs that possess 20 carbon atoms and three double bonds at minimum [48]. Those 16 FAs for which the proportion was on average larger than $0.4 \%$ or which seemed to be useful marker FAs [49] were included in the statistical calculations.

\section{Thiamine}

Thiamine was analysed in the whole body pools/ homogenates of sprat and herring according to Vuorinen et al. [41] by high-performance liquid chromatography (HPLC). Briefly, approximately $500 \mathrm{mg}$ of sample was weighed and homogenized (IKA Euro-ST P DV) with $2.0 \mathrm{ml}$ of $2 \%$ tricarboxylic acid (TCA), and the tube was incubated at $100{ }^{\circ} \mathrm{C}$ for $10 \mathrm{~min}$. Homogenisation was then repeated with $1.5 \mathrm{ml}$ of $10 \%$ TCA. The sample was centrifuged (Beckman Avanti J-30I) at $14,000 \times g$ for $15 \mathrm{~min}$ at a temperature of $+4{ }^{\circ} \mathrm{C}$. The supernatant was washed four times with an equal volume of ethyl acetatehexane $(3: 2)$. In order to convert thiamine forms into their corresponding thiochromes, an aliquot of $425 \mu \mathrm{l}$ of supernatant was taken and $75 \mu \mathrm{l}$ of $0.1 \%$ potassium hexacyanoferrate in $1.2 \mathrm{M}$ sodium hydroxide was added. The sample was filtered (Spartan 13/0.45 RC, S\&S) prior to analysis. Standards were subjected to the same procedure as the tissue samples. The injection volume was $20 \mu \mathrm{l}$ and the analysis time was 27 min using a linear gradient flow of eluents: eluent $\mathrm{A}$ was $0.5 \%$ acetonitrile and 99.5\% $25 \mathrm{mM}$ phosphate buffer, $\mathrm{pH}$ 8.4, and eluent $\mathrm{B}$ consisted of $25 \%$ dimethylformamide and $75 \% 25 \mathrm{mM}$ phosphate buffer, $\mathrm{pH}$ 8.4. All reagents were of analytical grade or better. The HPLC apparatus consisted of two Waters 510 pumps, a Waters 717 Plus Autosampler equipped with a cooling unit (sample tray at $+4{ }^{\circ} \mathrm{C}$ ), a thermostatic $\left(+35^{\circ} \mathrm{C}\right)$ column oven, a Waters 474 fluorescence detector and Millennium32 Chromatography Manager. The HPLC analysis separated thiamine monophosphate, thiamine pyrophosphate and unphosphorylated or free thiamine, which were summed as total thiamine (hereafter thiamine). A laboratory control sample (a subsample of large herring homogenate) was processed and analysed along with the samples for quality assurance.

\section{Data for thiamine and lipid in prey fish biomasses}

Relationships of the concentrations of $18: 1 n-9$ and DHA with the thiamine concentration in the annual biomasses of sprat and herring was analysed by including in the biomasses of herring only the age groups suitable as prey for salmon $[17,19]$. The annual biomass data for sprat of the BPr from 1974 to 2006 and herring of the BS from 1976 to 2005 were obtained from Mikkonen et al. [17], and the respective data for the thiamine concentrations in biomasses and for the calculation of FA concentrations and total lipid contents in sprat and herring biomasses from Keinänen et al. [18]. 


\section{Statistical analyses}

Multi-way analysis of variance (MANOVA) followed by the least squares means test (at the significance level of $p<0.05$ ) was applied when analysing the species (sprat and herring), spatial (northern BPr, BS and GoF) and seasonal (autumn and spring) dependencies of fish size, CF, lipid content, FA proportions and total thiamine concentration. Consistently with the suggestion of Warton and Hui [50] that percentage values could be used untransformed, the significances of statistical tests revealed the same results whether performed with percentage or arcsine-transformed data in the present study. The age relationship of the FA concentrations and that of the lipid content and thiamine concentration, as well as the ratio of the thiamine concentration to the content of lipids and some FAs of sprat and herring, were analysed by fitting either linear or polynomial models, whichever better fitted the data. Linear regressions were fitted for the annual concentrations of thiamine [18] as a function of the respective concentrations of 18:1n-9 and DHA for the sprat biomass in the BPr and herring biomass in the BS [17].

For multivariate statistical comparisons of detailed FA compositions of sprat and herring, principal component analysis (PCA) [51] was carried out. Prior to this, the FA data were log-transformed and subsequently standardized (variable deviations homogenized) to prevent the abundant components with large variances from dominating the analysis. In PCA, the samples originally positioned in a multidimensional space (as many coordinates as FAs analysed) were plotted in a newly formed two-coordinate system of principal components, PC1 and PC2. PC1 accounted for as much of the original data variability as possible and PC2 explained as much as possible of the remaining variation uncorrelated with the variation already explained by PC1. Biplot graphs were created to illustrate the compositional similarities and differences among the samples (the closer the position of the two samples in a biplot, the more similar is their composition) and to indicate correlations between the variables (when any two variables are connected with lines to the origin of the plot, and if the angle formed between the lines is close to $0^{\circ}$ or $180^{\circ}$, the variables have a strong positive or negative correlation, respectively).

Soft independent modelling of class analogy (SIMCA), a supervised classification method, was used to quantify the compositional differences between the fish sample groups (described qualitatively by a PCA biplot). When building the classification models, PCA was separately performed on each sample group (class) of the data set, and only the validated significant components (providing maximal information with minimal noise) were retained. Next, all the samples were projected into each class model and the residual distances were calculated. A sample was assigned to a class model if its residual distance from the model was below the chosen 95\% confidence limit for the class [52]. The Cooman plot was used to illustrate the classification result, and it displayed the orthogonal distances from all the samples to two selected class models at the same time. The method allowed the samples to belong to one, two or none of these classes, and absence of samples in the model intersection of the resulting Cooman plot indicated a significant compositional difference between the sample groups at the significance level of $p<0.05$.

The statistical analyses were performed with Statistical Analysis System (version 9.3) software [53], apart from PCA and SIMCA analysis, which were carried out using Sirius software (version 8.5, Pattern Recognition Systems, Norway, www.prs.no).

\section{Results}

\section{Fatty acid proportions}

The proportions of FAs and their sums according to species, sampling area and season are given in the Additional file 1 , and the mean and range of the proportions of individual fatty acids and their sums with sampling areas, seasons and age groups combined are given in the Additional file 2 .

The most prevalent component among SFAs, palmitic acid (16:0), was the most common of all FAs in herring. However, the proportions of it and SFAs in total did not differ between the species, but were higher in the BPr than in the GoF (Table 1). Moreover, the proportions of all SFAs were higher in spring than in autumn (Table 1).

Contrary to herring, the most common of all FAs in sprat was 18:1n-9, the dominant MUFA (Additional files 1 and 2). The proportions of $18: 1 n-9$ and MUFAs were not dependent on the season or area, even if the species were studied separately, but were higher in sprat than in herring (Table 1). In contrast, the percentages of the next most common MUFAs, palmitoleic acid (16:1n-7) and vaccenic acid (18:1n-7), were higher in herring than in sprat and, moreover, higher in the BS than in the GoF (Table 1).

PUFAs were predominantly composed of DHA and EPA, of which DHA was clearly more common, and the concentration of the third $n-3$ HUFA, docosapentaenoic acid (22:5n-3), was below $1 \%$ in both species. The third most common $n$-3 PUFA was alpha-linolenic acid (18:3n3) (Additional file 2). The proportions of $n-3$ PUFAs and DHA did not differ between the species, but instead were higher in spring than in autumn and higher in the GoF and BPr than in the BS (Table 1). No significant differences were detected in the proportion of EPA between the species, seasons or areas. The proportions of $18: 3 n-3$ 
Table 1 The effects of species, feeding area and season on the body size, condition factor (CF), lipid content (\%), total thiamine concentration ( $\mathrm{nmol} \mathrm{g}^{-1}$ ), the proportions of fatty acids (FAs) and their sums of sprat and herring caught in the Baltic Proper (BPr), Bothnian Sea (BS) and Gulf of Finland (GoF) in autumn and spring, tested by MANOVA and least squares means post hoc analysis (Lsmeans) for significant differences between the means

\begin{tabular}{|c|c|c|c|c|c|c|}
\hline \multirow[t]{2}{*}{ Variable } & \multicolumn{2}{|l|}{ Species } & \multicolumn{2}{|l|}{ Area } & \multicolumn{2}{|l|}{ Season } \\
\hline & $\begin{array}{l}\text { MANOVA } \\
p<\end{array}$ & $\begin{array}{l}\text { Lsmeans } \\
p<0.05\end{array}$ & $\begin{array}{l}\text { MANOVA } \\
p<\end{array}$ & $\begin{array}{l}\text { Lsmeans } \\
p<0.05\end{array}$ & $\begin{array}{l}\text { MANOVA } \\
p<\end{array}$ & $\begin{array}{l}\text { Lsmeans } \\
p<0.05\end{array}$ \\
\hline \multicolumn{3}{|l|}{ Body weight } & ns & ns & ns & ns \\
\hline \multicolumn{3}{|l|}{ Body length } & ns & ns & ns & ns \\
\hline \multicolumn{3}{|l|}{ CF } & 0.001 & $\mathrm{GoF}<\mathrm{BPr}, \mathrm{BS}$ & 0.001 & Spring $<$ autumn \\
\hline Lipid & 0.001 & Herring < sprat & 0.001 & $\mathrm{GoF}<\mathrm{BPr}<\mathrm{BS}$ & 0.001 & Spring $<$ autumn \\
\hline Total thiamine & ns & ns & ns & ns & ns & ns \\
\hline \multicolumn{7}{|c|}{ Saturated FAs (SFA) } \\
\hline $14: 0$ & 0.001 & Sprat $<$ herring & 0.05 & $\mathrm{BS}<\mathrm{BPr} ; \mathrm{GoF}=\mathrm{BPr}, \mathrm{BS}$ & 0.01 & Autumn $<$ spring \\
\hline $16: 0$ & ns & ns & 0.05 & $\mathrm{GoF}<\mathrm{BPr} ; \mathrm{BS}=\mathrm{BPr}, \mathrm{GoF}$ & 0.001 & Autumn $<$ spring \\
\hline 17:0 & ns & ns & ns & ns & ns & ns \\
\hline 18:0 & 0.05 & Herring < sprat & ns & $\mathrm{BS}<\mathrm{GoF} ; \mathrm{BPr}=\mathrm{BS}, \mathrm{GoF}$ & 0.01 & Autumn $<$ spring \\
\hline SFA & ns & ns & ns & $\mathrm{GoF}<\mathrm{BPr} ; \mathrm{BS}=\mathrm{BPr}, \mathrm{GoF}$ & 0.001 & Autumn $<$ spring \\
\hline \multicolumn{7}{|c|}{ Monounsaturated FAs (MUFA) } \\
\hline $16: 1 n-7$ & 0.05 & Sprat $<$ herring & 0.05 & $\mathrm{GoF}<\mathrm{BS} ; \mathrm{BPr}=\mathrm{BS}, \mathrm{GoF}$ & ns & ns \\
\hline $17: 1 n-8$ & 0.001 & Herring < sprat & ns & ns & ns & ns \\
\hline 18:1n-7 & 0.001 & Sprat $<$ herring & 0.01 & $\mathrm{GoF}<\mathrm{BS} ; \mathrm{BPr}=\mathrm{BS}, \mathrm{GoF}$ & 0.001 & Autumn $<$ spring \\
\hline $18: 1 n-9$ & 0.001 & Herring < sprat & ns & ns & ns & ns \\
\hline $20: 1 n-9$ & ns & ns & ns & ns & ns & ns \\
\hline MUFA & 0.001 & Herring < sprat & ns & ns & ns & ns \\
\hline \multicolumn{7}{|c|}{ Polyunsaturated FAs (PUFA) } \\
\hline $18: 2 n-6$ & 0.001 & Sprat $<$ herring & 0.01 & $\mathrm{BPr}, \mathrm{GoF}<\mathrm{BS} ; \mathrm{BPr}=\mathrm{GoF}$ & ns & ns \\
\hline $18: 3 n-3$ & ns & ns & 0.05 & $\mathrm{GoF}, \mathrm{BPr}<\mathrm{BS} ; \mathrm{BPr}=\mathrm{GoF}$ & 0.001 & Spring $<$ autumn \\
\hline $20: 2 n-6$ & ns & ns & ns & ns & ns & ns \\
\hline 20:4n-6 (ARA) & 0.01 & Sprat $<$ herring & ns & ns & 0.001 & Autumn $<$ spring \\
\hline 20:5n-3 (EPA) & ns & ns & ns & ns & ns & ns \\
\hline $22: 5 n-3$ & ns & ns & ns & $\mathrm{GoF}<\mathrm{BS} ; \mathrm{BPr}=\mathrm{GoF}, \mathrm{BS}$ & 0.001 & Spring $<$ autumn \\
\hline $22: 6 n-3(\mathrm{DHA})$ & ns & ns & 0.001 & $\mathrm{BS}<\mathrm{BPr}, \mathrm{GoF} ; \mathrm{BPr}=\mathrm{GoF}$ & 0.001 & Autumn $<$ spring \\
\hline PUFA & ns & ns & ns & ns & ns & ns \\
\hline$n-3$ PUFA & ns & ns & 0.05 & $\mathrm{BS}<\mathrm{BPr}, \mathrm{GoF} ; \mathrm{BPr}=\mathrm{GoF}$ & 0.05 & Autumn $<$ spring \\
\hline n-6 PUFA & 0.001 & Sprat $<$ herring & 0.01 & $\mathrm{BPr}, \mathrm{GoF}<\mathrm{BS} ; \mathrm{BPr}=\mathrm{GoF}$ & ns & ns \\
\hline$n-3 / n-6$ & 0.05 & Herring < sprat & 0.01 & $\mathrm{BS}<\mathrm{BPr}, \mathrm{GoF} ; \mathrm{BPr}=\mathrm{GoF}$ & 0.05 & Autumn $<$ spring \\
\hline
\end{tabular}

Statistical tests were performed for age group pools (total body homogenates) of sprat and herring (17 pools for sprat and 24 for herring), each consisting of $12-92$ specimens for sprat and 7-133 specimens for herring. The significances of differences in MANOVA and the Lsmeans test for the three effectors are given for each of the variables; $n$ s non-significant $(p \geq 0.05)$

and 22:5n-3 were higher in autumn than in spring and, moreover, higher in the BS than in the other sea areas or in the GoF, respectively (Table 1 ).

The proportion of $n-6$ PUFAs was much lower than that of $n$-3 PUFAs (Additional file 2). The most common n-6 PUFA was linoleic acid (18:2n-6), followed by ARA. The percentages of 18:2n-6 and ARA were, respectively, 1.3 and 1.5 times higher in herring than in sprat, and thus their proportions and that of $n-6$ PUFAs in general were significantly higher in herring (Table 1). The proportions of 18:2n-6 and $n-6$ PUFAs in total were also higher in the
BS than in the BPr or GoF. The proportion of ARA was instead season dependent, and was higher in spring than in autumn (Table 1), except in herring from the BS (Additional file 1).

\section{Body characteristics}

The total lipid content varied from 1.9 to $17.3 \%$ (on a fresh weight basis) in sprat and from 2.0 to $8.8 \%$ in herring, and was significantly higher in sprat (on average 9.3\%) than in herring (5.6\%) (Table 1; Fig. 2). Both species were fattier in autumn than in spring. Moreover, the lipid 
content of both species differed between the sea areas; it was highest in the BS and lowest in the GoF (Table 1; Fig. 2). In sprat, the lipid content decreased according to age ( $\left.y=12.68-088 \mathrm{x}, \mathrm{R}^{2}=0.193, p<0.05, \mathrm{~N}=17\right)$, but in herring there was no significant relationship between the lipid content and age $\left(\mathrm{y}=5.78-0.14 \mathrm{x}+0.02 \mathrm{x}^{2}\right.$, $\mathrm{R}^{2}=0.063, p>0.05, \mathrm{~N}=30$ ). The CF of prey fish was lower in spring than in autumn and lower in the GoF than in the BPr or the BS (Table 1).

\section{Fatty acid contents}

Sprat on average contained more of all major single FAs (i.e., 18:1n-9, 16:0, DHA and EPA), as well as less prevalent FAs (i.e., 14:0, 18:0 and 18:3n-3), than herring (Table 2; Fig. 3). Consistently, the contents of SFAs, MUFAs, PUFAs and $n-3$ PUFAs were higher in sprat than in herring (Table 2; Fig. 4). Only the contents of 16:1n-7 and 18:1n-7, and individual $n-6$ PUFAs (18:2n-6, 20:2n-6 and ARA), and thus of $n-6$ PUFAs in total, did not differ between the species $(p>0.05)$ (Table 2).

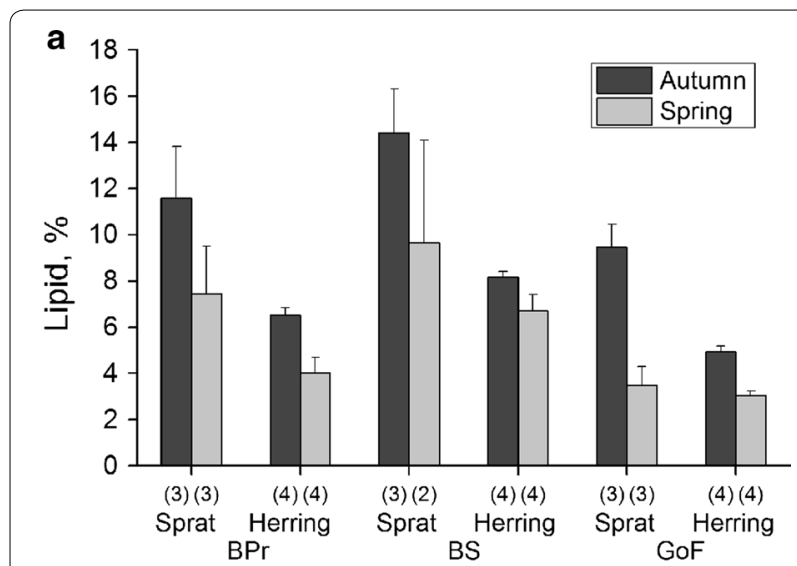

b

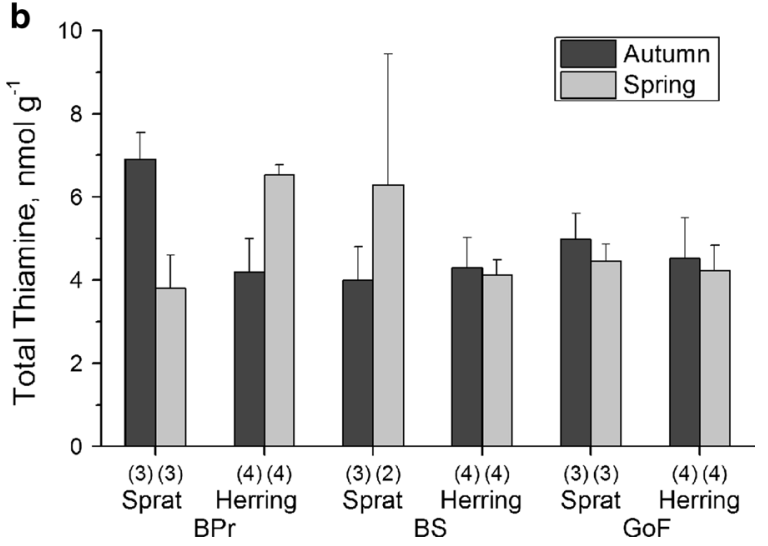

Fig. 2 Mean $( \pm S E)$ a lipid content and $\mathbf{b}$ thiamine concentration in pools of whole herring and sprat according to sampling location and season. Number of samples in parentheses; pools of sprat consisted of 12-92 and of herring 7-133 specimens
Table 2 The mean and range (minimum and maximum) of the body weight, total length and condition factor (CF) of sprat and herring with sampling areas (the Baltic Proper, Bothnian Sea and Gulf of Finland), seasons (autumn and spring) and age groups combined, and the lipid content (in wet weight), total thiamine concentration, and the contents of individual fatty acids and their sums (i.e., the main FA groups) in age group pools of sprat (17 pools, each consisting of 12-92 specimens) and herring (24 pools, each consisting of 7-133 specimens)

\begin{tabular}{|c|c|c|c|c|c|}
\hline & \multicolumn{2}{|l|}{ Sprat } & \multirow[t]{2}{*}{$p<$} & \multicolumn{2}{|c|}{ Herring } \\
\hline & Mean & Range & & Mean & Range \\
\hline Weight, g & 8.38 & $2.40-12.0$ & - & 18.1 & $2.71-42.27$ \\
\hline Length, mm & 113.4 & $79-130$ & - & 140.2 & 83-183 \\
\hline CF & 0.55 & $0.45-0.69$ & - & 0.57 & $0.48-0.69$ \\
\hline Lipid, \% & 9.32 & $1.90-17.3$ & 0.001 & 5.56 & $2.01-8.80$ \\
\hline $\begin{array}{l}\text { Total thiamine, } \\
\mathrm{nmol} \mathrm{g}^{-1}\end{array}$ & 5.002 & $2.519-9.434$ & ns & 4.649 & $2.538-7.213$ \\
\hline \multicolumn{6}{|l|}{ Saturated FAs (SFA) } \\
\hline $14: 0, \mathrm{mg} \mathrm{g}^{-1}$ & 3.55 & $0.60-5.92$ & 0.05 & 2.53 & $1.15-3.85$ \\
\hline $16: 0, \mathrm{mg} \mathrm{g}^{-1}$ & 20.01 & $4.01-37.42$ & 0.01 & 11.90 & $4.55-18.00$ \\
\hline $17: 0, \mathrm{mg} \mathrm{g}^{-1}$ & 0.46 & $0.07-0.78$ & 0.001 & 0.24 & $0.00-0.56$ \\
\hline $18: 0, \mathrm{mg} \mathrm{g}^{-1}$ & 2.76 & $0.79-4.82$ & 0.001 & 1.43 & $0.39-2.53$ \\
\hline Total SFA, mg g ${ }^{-1}$ & 27.58 & $5.57-49.90$ & 0.01 & 16.72 & $6.31-25.17$ \\
\hline \multicolumn{6}{|c|}{ Monounsaturated FAs (MUFA) } \\
\hline $16: 1 n-7, \mathrm{mg} \mathrm{g}^{-1}$ & 4.78 & $0.68-8.11$ & ns & 3.87 & $1.32-10.09$ \\
\hline $17: 1 n-8, \mathrm{mg} \mathrm{g}^{-1}$ & 0.52 & $0.07-1.00$ & 0.001 & 0.24 & $0.11-0.45$ \\
\hline 18:1n-7, $\mathrm{mg} \mathrm{g}^{-1}$ & 2.98 & $0.70-6.18$ & ns & 2.65 & $1.13-5.42$ \\
\hline $18: 1 n-9, \mathrm{mg} \mathrm{g}^{-1}$ & 25.04 & $3.91-47.54$ & 0.001 & 9.34 & $4.13-14.58$ \\
\hline $20: 1 n-9, \mathrm{mg} \mathrm{g}^{-1}$ & 0.72 & $0.09-3.04$ & ns & 0.47 & $0.19-1.03$ \\
\hline Total MUFA, $\mathrm{mg} \mathrm{g}^{-1}$ & 34.98 & $5.56-63.49$ & 0.001 & 17.08 & $7.29-31.35$ \\
\hline \multicolumn{6}{|c|}{ Polyunsaturated FAs (PUFA) } \\
\hline $18: 2 n-6, \mathrm{mg} \mathrm{g}^{-1}$ & 3.09 & $0.49-5.81$ & ns & 2.37 & $0.89-4.52$ \\
\hline $18: 3 n-3, \mathrm{mg} \mathrm{g}^{-1}$ & 2.36 & $0.07-5.12$ & 0.01 & 1.26 & $0.29-3.46$ \\
\hline $20: 2 n-6, \mathrm{mg} \mathrm{g}^{-1}$ & 0.55 & $0.02-1.02$ & ns & 0.88 & $0.17-6.56$ \\
\hline $\begin{array}{l}\text { 20:4n-6 (ARA), } \\
\mathrm{mg} \mathrm{g}^{-1}\end{array}$ & 0.37 & $0.00-1.03$ & ns & 0.41 & $0.08-0.74$ \\
\hline $\begin{array}{l}\text { 20:5n-3 (EPA) } \\
\mathrm{mg} \mathrm{g}^{-1}\end{array}$ & 6.27 & $1.35-13.59$ & 0.01 & 3.93 & $1.29-7.40$ \\
\hline $22: 5 n-3, \mathrm{mg} \mathrm{g}^{-1}$ & 0.37 & $0.00-1.06$ & ns & 0.28 & $0.00-0.67$ \\
\hline $\begin{array}{l}\text { 22:6n-3 (DHA) } \\
\mathrm{mg} \mathrm{g}^{-1}\end{array}$ & 10.13 & $4.63-18.94$ & 0.001 & 6.35 & $2.39-9.75$ \\
\hline Total PUFA, $\mathrm{mg} \mathrm{g}^{-1}$ & 25.69 & $7.13-50.76$ & 0.01 & 16.81 & $5.59-31.62$ \\
\hline$n-3$ PUFA, $\mathrm{mg} \mathrm{g}^{-1}$ & 21.63 & $6.37-43.22$ & 0.01 & 13.09 & $4.35-24.85$ \\
\hline$n-6$ PUFA, $\mathrm{mg} \mathrm{g}^{-1}$ & 4.07 & $0.75-7.54$ & ns & 3.71 & $0.91-10.83$ \\
\hline
\end{tabular}

The statistical significance of differences in variables between sprat and herring is indicated with the three classes of probability $(p<0.05,0.01$ or 0.001$)$, with $n s$ non-significant, and the significantly larger means and ranges are indicated in italics

SIMCA analysis did not reveal significant differences in the contents of FAs between sprat and herring when autumn and spring results from all areas were included 


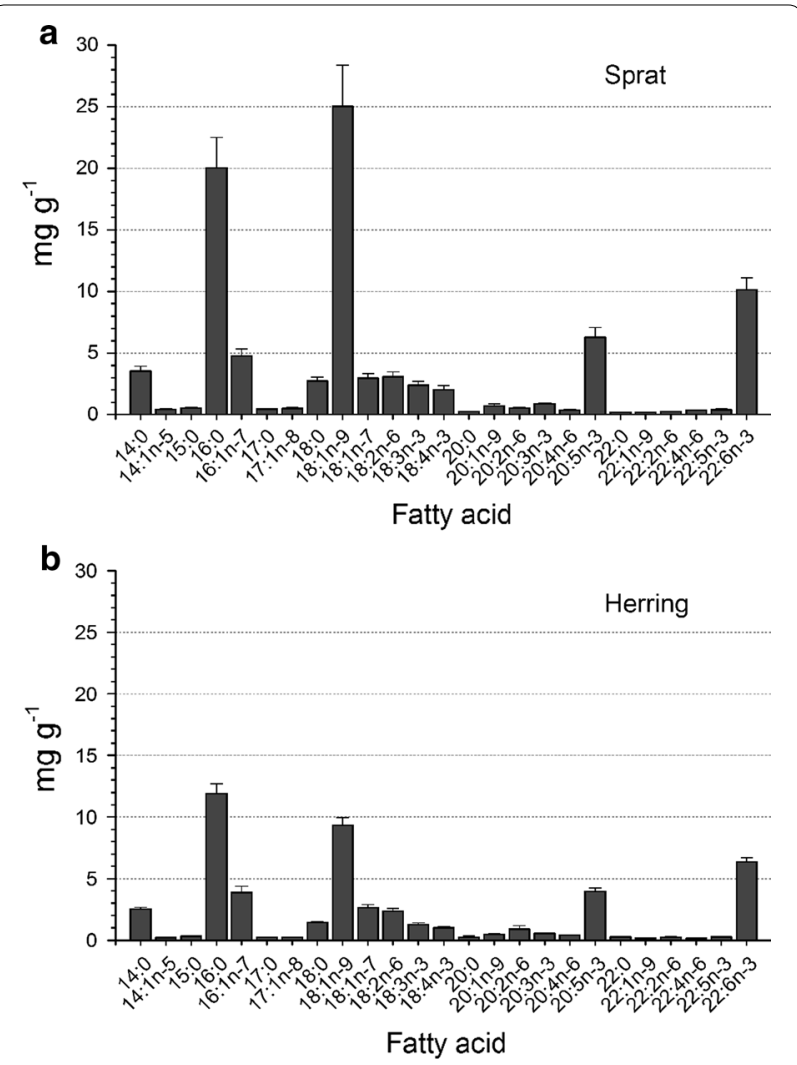

Fig. 3 Mean ( \pm SE) concentrations $\left(\mathrm{mg} \mathrm{g}^{-1}\right.$ ) of fatty acids in the whole body homogenates of $\mathbf{a}$ sprat and $\mathbf{b}$ herring with seasons, sampling areas and age groups combined

in the analysis. Principal components 1 and 2 together explained $46 \%$ of the total variation in the fish FA content. However, according to the PCA biplot, some shift appeared on the basis of the FA composition between the species (Fig. 5a): all individual $n-6$ PUFAs, as well as $18: 1 n-7,16: 1 n-7$ and $22: 5 n-3$, were associated with herring specimens and plotted far from sprat specimens, whereas 18:0 and DHA appeared to be better associated with sprat than herring specimens (Fig. 5a).

When the FA contents from autumn alone from all areas were included in the PCA, the difference between sprat and herring was significant $(p<0.05)$ according to SIMCA classification (Fig. 5b). Principal components 1 and 2 explained $70 \%$ of the variation. The clearest differences between the species in autumn were in the composition of all individual $n-6$ PUFAs and 18:1n-7, 16:1n-7, $20: 1 n-9$ and $22: 5 n-3$, which were now distinctly associated with herring, whereas the main constituent, 18:1n-9, correlated better with sprat.

In herring, the contents of FAs significantly differed in autumn between the BS and GoF, but the values for the BPr, being between these two areas, did not differ from them (Fig. 5c). Principal components 1 and 2 of the PCA model accounted for $77 \%$ of the variation in FA contents. It demonstrated that ARA, 20:2n-6 and 22:5n-3 most clearly, and also $18: 1 n-7$, were more common in herring of the BS than the GoF, whereas 14:0, 16:0 and $18: 1 n-9$ appeared to be more common in herring of the GoF. In spring, the FA composition of herring did not differ between the areas, and that of sprat did not differ between areas in either the autumn or spring.

The difference in the contents of FAs between autumn and spring was significant in sprat (Fig. 6a), but not in herring, despite a slight shift also appearing in herring between the seasons (Fig. 6b). In sprat, 18:0, ARA and DHA were, according to the PCA model, most clearly related to spring and PUFAs 22:5n-3, 18:3n-3 and EPA to autumn (Fig. 6a).

\section{Fatty acid composition in relation to age}

The concentration of 16:0 decreased with age only in sprat (Fig. 7), similarly to the lipid content. The concentration of $18: 1 n-9$ tended to be lowest in the youngest fish in both species, and in sprat it tended to increase as a function of age and decrease again at older ages (Fig. 7). The DHA concentration changed significantly and in the opposite way to that of $18: 1 n-9$. The highest DHA concentrations were recorded in the youngest fish and the lowest in the oldest ones in both prey species. However, the model more strongly explained the change in the concentration of DHA with respect to age in sprat than in herring. The difference in the concentration of DHA between the species was largest in the youngest age groups, with sprat containing 1.8 times more DHA than herring at the age of one year. The concentrations of the two minor MUFAs, $16: 1 n-7$ and 18:1n-7, which appeared to be characteristic for herring, increased with age in herring $\left(16: 1 n-7: \mathrm{y}=0.241+0.049 \mathrm{x}, R^{2}=0.214, p<0.01\right.$, $\mathrm{N}=30 ; 18: 1 n-7: \mathrm{y}=0.217+0.017 \mathrm{x}, R^{2}=0.110, p<0.05$, $\mathrm{N}=30$ ), but their age relationship was not significant in sprat (Additional file 3).

\section{Thiamine concentrations}

The thiamine concentration did not differ significantly between sprat and herring or between the areas or seasons (Table 1; Fig. 2). The change in the thiamine concentration with prey fish age was not significant, either, although it tended to increase with age in sprat (sprat: $\mathrm{y}=3.68+0.35 \mathrm{x} ; R^{2}=0.173 ; p>0.05 ; \mathrm{N}=17$, herring: $\left.\mathrm{y}=3.01+0.88 \mathrm{x}-0.08 \mathrm{x}^{2} ; R^{2}=0.095 ; p>0.05 ; \mathrm{N}=30\right)$.

The concentration of thiamine per unit of body lipid increased linearly and significantly with age in sprat, but the change was not significant in herring (Fig. 8). Likewise, the ratio of thiamine to $18: 1 n-9$ increased 

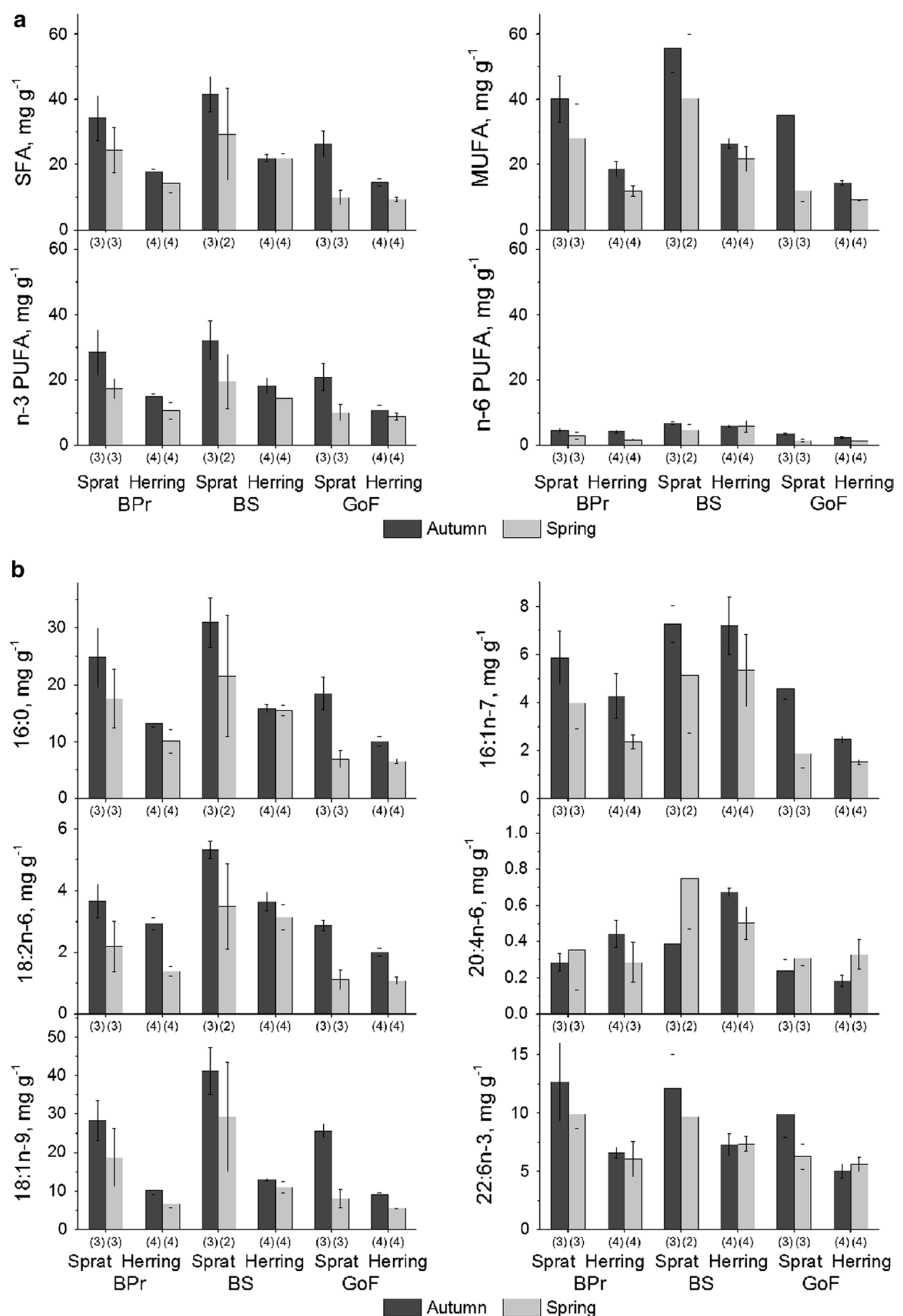

Fig. 4 Mean $( \pm S E)$ concentrations ( $\mathrm{mg} \mathrm{g}^{-1}$ ) of a saturated (SFAs), monounsaturated (MUFAs) and polyunsaturated fatty acids (PUFAs), $n$-3 PUFAs and $n-6$ PUFAs, and b palmitic acid (16:0), palmitoleic acid (16:1n-7), linoleic acid (18:2n-6), arachidonic acid (20:4n-6), oleic acid (18:1n-9) and docosahexaenoic acid (22:6n-3) in pools of sprat and herring caught from the Baltic Proper (BPr), Bothnian Sea (BS) and Gulf of Finland (GoF) in autumn and spring. Numbers of sample pools (total body homogenates) are indicated; pools of sprat consisted of 12-92 and of herring 7-133 specimens. Note the different scales in $(\mathbf{b})$ 


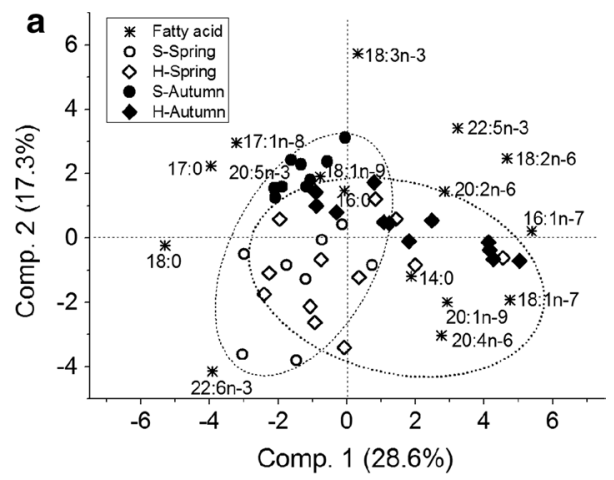

SIMCA classification: Sprat / Herring, $p>0.05$

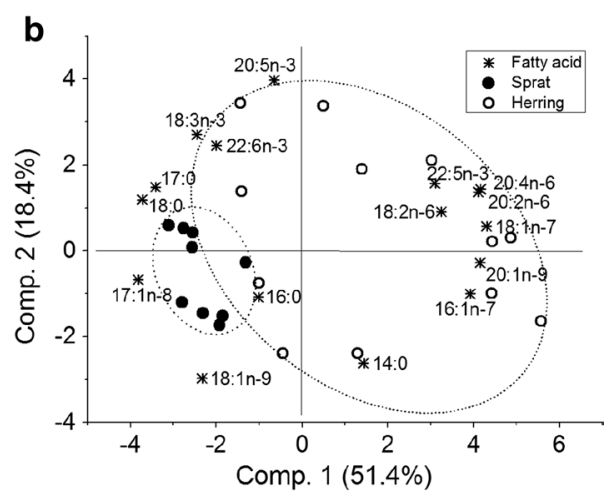

SIMCA classification: Sprat / Herring, $p<0.05$

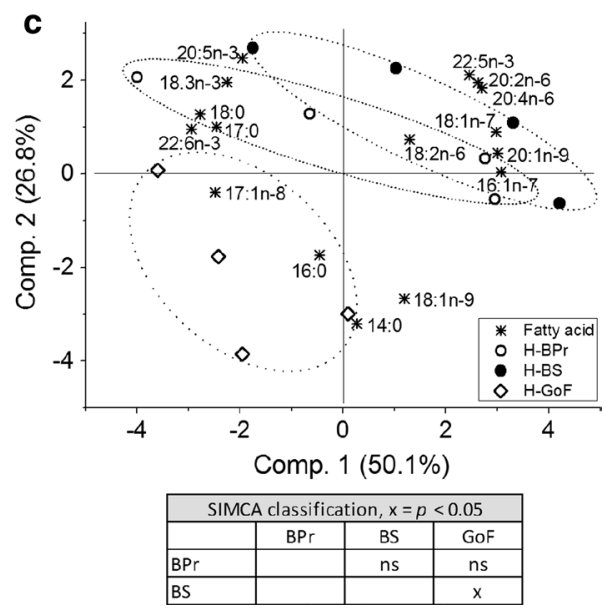

Fig. 5 PCA biplots with principal components 1 and 2 and following paired SIMCA test results for the concentrations of fatty acids in the whole body of prey fish caught from the Baltic Proper (BPr), Bothnian Sea (BS) and Gulf of Finland (GoF), including a all sprat (S) and herring $(\mathrm{H})$ in autumn and spring, b all sprat and herring in autumn and $\mathbf{c}$ all herring $(\mathrm{H}-\mathrm{BPr}, \mathrm{H}-\mathrm{BS}$ and $\mathrm{H}-\mathrm{GoF})$ in autumn. Each symbol refers to a pool (whole body homogenate), which for sprat consisted of 12-92 specimens and for herring 7-133 specimens

significantly with age in sprat, but not in herring (Fig. 8). The increase in the ratio thiamine/DHA with respect to age was clearest among the FAs, so that the change was

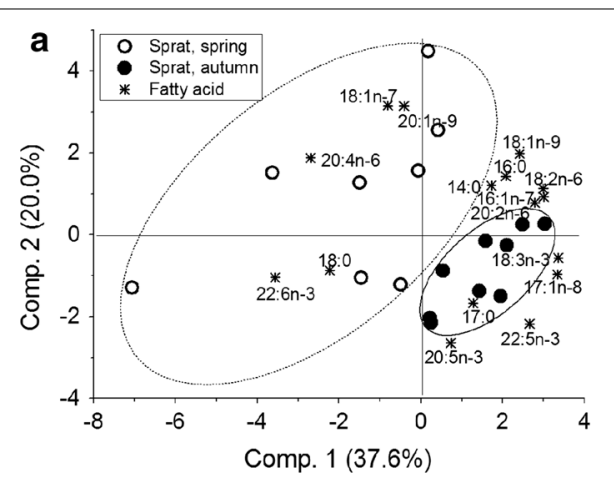

SIMCA classification: Spring / Autumn, $p<0.05$

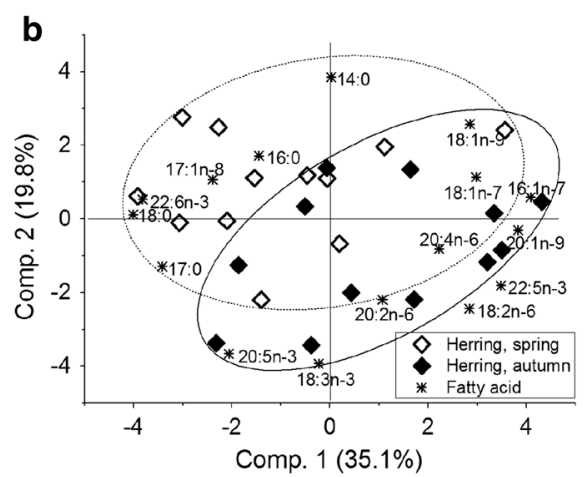

SIMCA classification: Spring / Autumn, $p>0.05$

Fig. 6 Biplots from the PCA of concentrations of fatty acids with principal components 1 and 2 and following paired SIMCA test results for $\mathbf{a}$ sprat and $\mathbf{b}$ herring caught from the Baltic Proper, Bothnian Sea and Gulf of Finland in autumn and spring. Each symbol refers to a pool (whole body homogenate), which for sprat consisted of 12-92 specimens and for herring 7-133 specimens

highly significant in sprat and also significant in herring (Fig. 8 and Additional file 4). In the case of 18:1n-9, the ratio of thiamine to the FA differed more between the youngest sprat and herring than with the other FAs, but all the ratios of thiamine to FAs were higher in young herring than in young sprat (Additional file 4).

In the sprat biomass of the $\mathrm{BPr}$, the relationships between the annual thiamine concentration and 18:1n-9 and DHA were negative during the time period 19742006 (Fig. 9). In the BS (1976-2005), the thiamine concentration of the herring biomass was similarly inversely related to the DHA concentration, but the relationship between the thiamine concentration and 18:1n-9 was positive. The average annual thiamine concentration was considerably higher in the herring biomass from the BS than in the sprat biomass from the BPr (Fig. 9). In the sprat biomass, the average concentrations of $18: 1 n-9$ and DHA were, respectively, 3 and 2.6 times higher than in the herring biomass. 


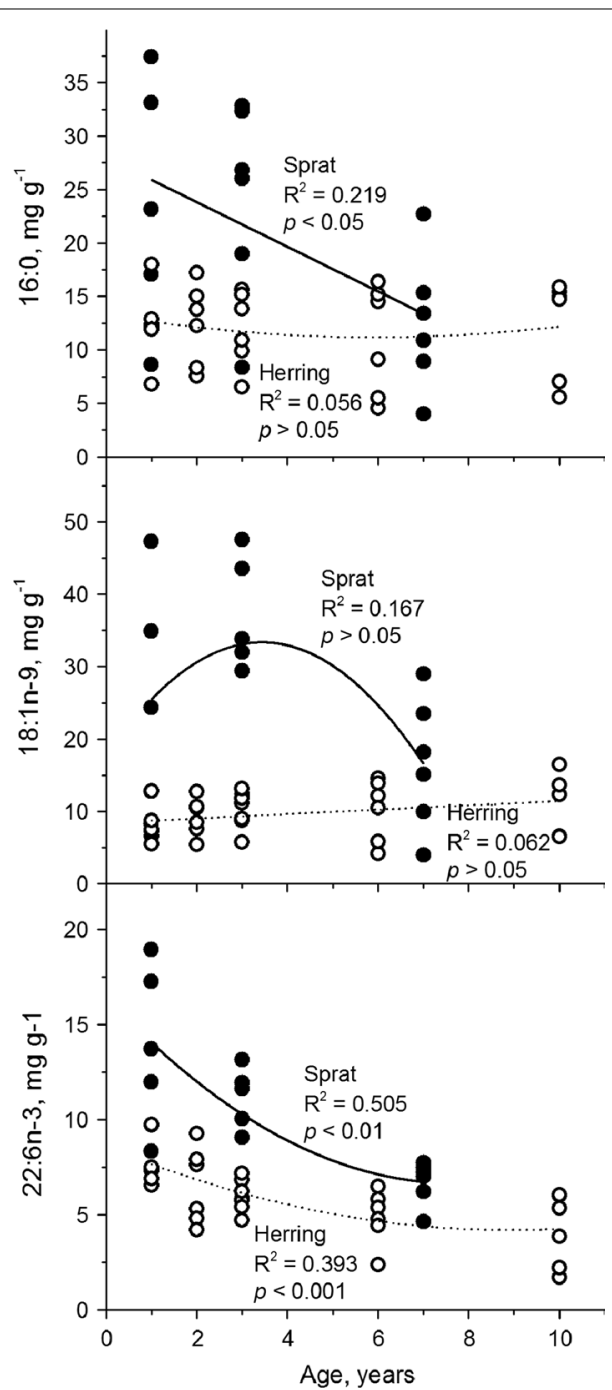

Fig. 7 Concentrations $\left(\mathrm{mg} \mathrm{g}^{-1}\right)$ of palmitic acid (16:0), oleic acid $(18: 1 n-9)$ and docosahexaenoic acid (22:6n-3) as a function of the age of sprat and herring with sampling areas and seasons combined. The coefficient of determination $\left(R^{2}\right)$ and significance of the fitted models are given. Each symbol refers to a pool (whole body homogenate), which for sprat consisted of 12-92 specimens and for herring 7-133 specimens

\section{Discussion}

Species-specific differences in the FA composition of sprat and herring were particularly evident in autumn, when the whole body lipid content of both prey fish species was highest, and differed most between the species. Because sprat can accumulate lipids more readily under favourable growth conditions compared to herring [18], the lipid content in sprat can vary more than in herring. That became apparent as larger age-dependent variation in sprat. Consistently with earlier studies [18, 35, 41], the average lipid content of whole sprat was higher than

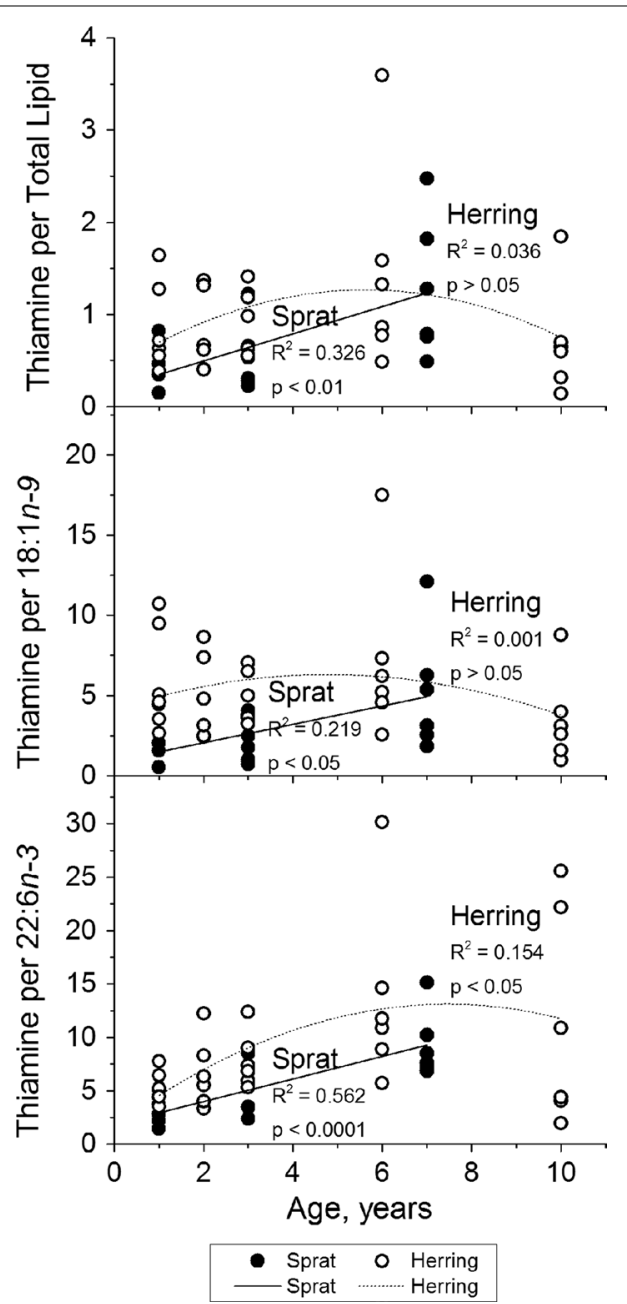

Fig. 8 Ratio of the concentration of thiamine to the content of lipid and concentration of oleic acid (18:1n-9) and docosahexaenoic acid (22:6n-3) as a function of the age of sprat and herring with sampling areas and seasons combined. The coefficient of determination $\left(R^{2}\right)$ and significance of the fitted model are given. Each symbol refers to a pool (whole body homogenate), which for sprat consisted of 12-92 specimens and for herring 7-133 specimens

that of herring, and the youngest sprat had the highest whole body lipid content. Spatial differences in the FA composition of prey fish were also partly related to their lipid content, i.e. to the low CF of prey fish in the GoF and the highest lipid content occurring in the BS. However, similarly to Budge et al. [54], the variation in the FA proportions within fish species between the feeding locations was less than that between the species. Røjbek et al. [35] also detected no spatial differences in the FA composition of sprat or herring, although their samples were all taken from a relatively restricted area around the Bornholm Basin. The differences in the FA composition between sprat and herring in the same sea area presumably largely arise from species-specific genetic differences 

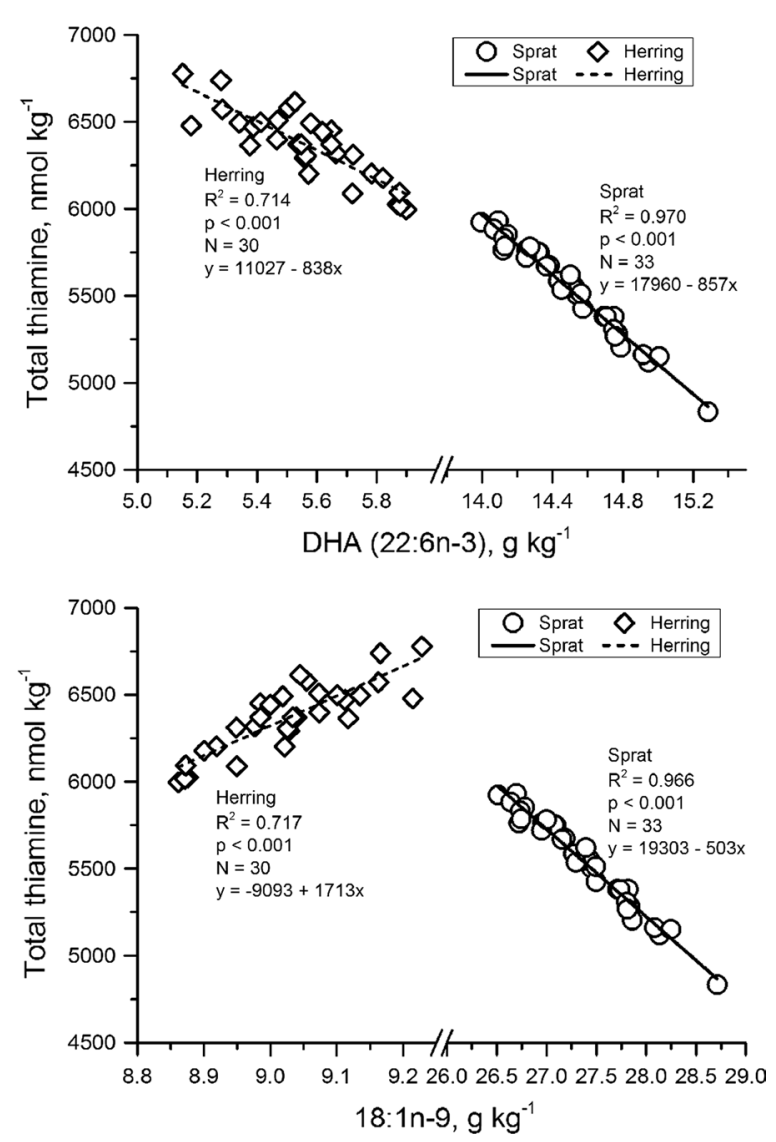

Fig. 9 Thiamine contents plotted against docosahexaenoic acid (DHA, 22:6n-3) and oleic acid (18:1n-9) contents in the sprat biomass of the Baltic Proper in 1974-2006 and in the herring $(<19 \mathrm{~cm})$ biomass of the Bothnian Sea in 1976-2005. The thiamine and lipid data for the calculation of FA concentrations and data on sprat and herring biomass were taken from Keinänen et al. [18] and Mikkonen et al. [17], respectively

in the accumulation and utilisation of FAs, and partly arise from feeding preferences [55].

Sprat lipid, consistent with Røjbek et al. [35], was characterized by MUFAs, especially 18:1n-9. The species specificity of $18: 1 n-9$ is evident, as fish in the study by Røjbek et al. [35] were caught from the southern BPr, and our samples were from the three more northern sea areas, between which no differences were observed in the contents of $18: 1 n-9$ or MUFAs in sprat. Moreover, 18:1n-9 was the only major individual FA whose proportions were related to the species but not to the season or area. Sprat in the Atlantic [56] have been found to contain lower proportions of $18: 1 n-9$ than sprat in the Baltic Sea [35]. However, the Atlantic specimens instead contained more of the long-chain MUFAs 20:1n-9 and 22:1n-11 [56]. The percentage of MUFAs in the muscle of adult sprat has been found to vary in the southern Baltic
Sea from the west to the east; it was lowest in the western ICES subdivision 24 and highest in the most eastern subdivision 26 [39]. In that study, the percentages of DHA and PUFAs, as well as the weight of fish, displayed the opposite relationship to the proportion of MUFAs. Apart from dietary changes, the reason for this variation could be the variation in the lipid content of sprat [39]. A similar reciprocal relationship was found in the present study between the proportions of the dominant PUFA and MUFA, DHA and 18:1n-9, when examined with respect to age, and the relative changes were more pronounced in sprat than in herring.

In contrast to a review by Tocher [48] of teleost FAs, 18:2n-6 instead of ARA was the most common $n-6$ PUFA in both herring and sprat. Although the proportion of ARA increased considerably from autumn to spring, it remained much lower than that of its metabolic precursor, 18:2n-6. Aro et al. [37] did not report any ARA in fillets of herring caught from the southern BS, but the proportion of 18:2n-6 was close to that in the whole body of herring of the present study. Although $n-6$ PUFAs in general were associated with herring, they, and specifically $18: 2 n-6$, were also associated with the BS. As microalgae of freshwater origin produce more 18:2n-6 than marine species [57], and the salinity decreases from ca. $0.8 \%$ in the southern BPr to ca. $0.5 \%$ in the BS [58], a higher proportion of $n-6$ PUFAs in the BS than in the other areas may partly reflect its freshwater character.

A larger variation in the PCA model among herring than among sprat reflected the different feeding preferences of these species. Moreover, differences in the spawning time and area between sprat and herring [23] affect the food availability and thus FA contents of the young-of-the-year fish. According to Casini et al. [59], sprat solely feed on zooplankton, and sprat and smaller herring largely feed on the same zooplankton species [59-61]. The growth rate of sprat declines with age, so that its total length seldom exceeds $15 \mathrm{~cm}$ [39]. Herring vary in feeding preferences according to their size: they are mainly zooplankton feeders up to the length of $16-18 \mathrm{~cm}$ [55], which is within the range of prey sizes preferred by salmon $[19,21]$ and within the range of sizes of prey fish included in the present study. However, even smaller herring in winter and larger herring as a function of size feed increasingly on benthic invertebrates $[55,59$, 62]. This is probably the reason for the clear increase in the content of $16: 1 n-7$ and $18: 1 n-7$ in herring with age, a change that was more pronounced in $16: 1 n-7$ than in its elongation product, 18:1n-7. Although in herring these MUFAs were most common in the BS, their proportions in sprat did not differ between the areas or age. Apparently, these MUFAs are associated with low salinity environments such as the BS [58], as also found by Huovila 
[63], but at the same time with herring prey organisms. The FAs $16: 1 n-7$ and $18: 1 n-7$ in clupeids could thus be used to indicate their feeding behaviour.

A high proportion of DHA, which in coldwater fish is among the most important components of membrane phospholipids [57], was most clearly associated with a low lipid content in both prey fish species. This was emphasized in spring in the GoF, where the low CF of prey fish resulted from high food competition [61, 64, 65]. The growth rate of clupeids in the Baltic Sea is highest in early summer and lowest in late autumn and winter $[62,66]$. As the lipid reserves that had accumulated during the primary growth season in muscle and viscera are depleted during periods of feeding deprivation [67], the proportion of lipid in body structures, such as membranes, is emphasized. Although the proportion of DHA was on average higher in the leanest prey fish containing the least storage lipid, the concentration of DHA was lowest in these fish. Røjbek et al. [35] demonstrated similar lipid dependence in the proportions and concentrations with PUFAs. Accordingly, herring of the BS, where the prey fish had the highest lipid content during the sampling years, on average had higher concentrations of DHA than herring in the other areas. However, as a fattier species, sprat in the BPr and even in the GoF contained DHA at higher concentrations than herring in the BS. Although the DHA concentration decreased with age in both species, in young sprat it was nearly double that of young herring. In the youngest herring and oldest sprat, the DHA concentrations were similar. The concentration of $18: 1 n-9$ had the opposite age relationship to that of DHA, especially in sprat, in which the concentrations of both FAs were higher in all age groups than in herring. Thus, not only prey species and consequently feeding area, but also the composition of prey fish age groups, as a result of the success of annual recruitment, affects the dietary FA composition of salmon feed.

The highest 18:1n-9 concentration in different age groups, particularly in sprat, appeared to co-occur with their highest thiamine concentration, presented with a larger data set for the thiamine concentrations in Keinänen et al. [18]. In contrast, the highest DHA concentration in sprat coincided with their lowest thiamine concentration, i.e., in the youngest sprat (cf. Keinänen et al. [18]). When relating the thiamine concentration to the concentrations of the most prevalent FAs, 16:0, 18:1n9 and DHA, the ratio thiamine/FA always increased linearly as a function of sprat age, being lower in the youngest sprat than in the youngest herring. The thiamine concentration per unit lipid in the sprat biomass in the BPr was lowest during the years of high M74 mortality [18]. However, thiamine deficiency in salmon is not related to the dietary thiamine concentration as such, but to a high lipid content in the prey fish biomass [18]. The co-occurrence of the lowest thiamine concentration and highest DHA concentration in the youngest sprat and herring suggests that $n-3$ HUFA may reduce the levels of thiamine already present in prey fish. This appeared as the lowest ratio of thiamine to DHA in the youngest prey fish and in the annual biomasses as a decreasing thiamine concentration with an increasing DHA concentration.

Thiamine deficiency in salmon was at its worst during several successive years of strong recruitment of sprat $[17,30]$. This was also observed in the stomach contents of salmon, in which the youngest sprat were most numerous during the years of high M74 mortalities, i.e., 1994-1997, than earlier [19]. Young age groups of sprat (up to 4-year-olds) generally constitute the greater part of the sprat stock of the Baltic Sea [24]. During the last few decades, when the winters have been mild, salmon have increasingly continued to feed during winter [16]. Because sprat spawn later in summer than herring [23], but attain an appropriate size to be preyed on by salmon by the end of the year [19], the salmon diet has consisted more of young sprat in relation to herring in winter than in summer [16]. This has further increased preying on young sprat by salmon during the strong recruitment years of sprat, especially in the BPr, which is the main feeding area of salmon in the Baltic Sea [68].

Thiamine deficiency of salmon had already been linked to a high dietary lipid content [18] and increased oxidative stress $[14,15,69]$. In the years of high M74 incidence, the abundance of specifically young sprat resulted in an ample lipid supply, and thus also an ample DHA supply, for salmon. Evidently, thiamine deficiency is specifically related to a high DHA concentration of the prey biomass. This is supported by the finding of Pickova et al. $[15,69]$ that the eggs of salmon with offspring suffering from M74 contained more DHA than those of healthy females. Interestingly, M74 mortality was almost non-significant in the years 2003-2005 [28-30], i.e., during the years when the samples of this study were collected. By these years, the sprat stock in the Baltic Sea had decreased to its lowest level since its abrupt strengthening at the beginning of the 1990s [28]. Apart from the annual variation in the incidence of thiamine deficiency, the thiamine concentration of the salmon eggs also varies within years between female individuals of each river, leading to differences in offspring M74 mortality (from 0 to 100\%) [13, 26]. Stomach analyses have demonstrated that there may be individual differences in salmon feeding behaviour [21]. However, despite consuming the same prey, individual salmon can also differ in terms of their retention of lipids [57]. Nevertheless, the dietary FA composition should be reflected in the FA profiles of salmon [31-33]. Thus, the results of the present study are also important 
in determining the feeding area of salmon caught while returning to spawn [70].

\section{Conclusions}

The FA compositions of sprat and herring differ and the relative proportions of these main prey fish of salmon differ between the feeding areas of salmon in the Baltic Sea. This potentially allows the feeding history and feeding areas of salmon caught while returning to spawn to be determined from their FA composition. The lipids of Baltic sprat are characterized by the most prevalent MUFA, 18:1n-9, whereas $n-6$ PUFAs and two minor MUFAs, $16: 1 n-7$ and 18:1n-7, are present in higher proportions in herring than in sprat. However, an increase in the prey lipid content increases the proportion of $n$ 3 HUFAs, especially that of DHA, in the salmon diet. Thus, the supply of $18: 1 n-9$ and DHA to salmon is higher from sprat than herring, and the supply of DHA is highest from young sprat. Unsaturated FAs, specifically $n-3$ HUFAs, are easily oxidized and predispose salmon to oxidative stress. General oxidative stress, mainly due to the peroxidation of $n-3$ HUFAs, exacerbated by free radical oxidation of the prevalent $18: 1 n-9$, reduces thiamine levels because of the antioxidant property of thiamine. This is the case when the supply of prey fish lipids has considerably increased but the availability of additional antioxidants is restricted, as it is during the prespawning fasting period of salmon.

\section{Additional files}

Additional file 1. The mean ( $\pm \mathrm{SE}$ ) proportions of fatty acids and their sums in total body homogenates of pooled (number of pools 2-4) sprat and herring (number of fish in pools 12-92 for sprat and 7-133 for herring) from the three Baltic Sea areas in autumn and spring.

Additional file 2. The mean and range (minimum and maximum) of the proportions of individual fatty acids and their sums (i.e., the main FA groups) with sampling areas (the Baltic Proper, Bothnian Sea and Gulf of Finland), seasons (autumn and spring) and age groups combined in age group pools of sprat (17 pools, each consisting of 12-92 specimens) and herring (24 pools, each consisting of 7-133 specimens).

Additional file 3. Relationships of fatty acid concentrations $\left(\mathrm{mg} \mathrm{g}^{-1}\right)$ as a function of the age of sprat and herring with sampling areas (Baltic Proper Bothnian Sea and Gulf of Finland) and seasons (autumn and spring) combined. The coefficient of determination $\left(R^{2}\right)$ and significance of the fitted model are given. Each symbol refers to a pool (whole body homogenate), which for sprat consisted of 12-92 specimens and for herring 7-133 specimens.

Additional file 4. Ratio of the concentration of thiamine to the concentration of fatty acids and their sums as a function of the age of sprat and herring with sampling areas (Baltic Proper, Bothnian Sea and Gulf of Finland) and seasons (autumn and spring) combined. The coefficient of determination $\left(R^{2}\right)$ and significance of the fitted model are given. Each symbol refers to a pool (whole body homogenate), which for sprat consisted of 12-92 specimens and for herring 7-133 specimens.

\section{Abbreviations}

ARA: arachidonic acid; BPr: Baltic Proper; BS: Bothnian Sea; CF: condition factor; DHA: docosahexaenoic acid; EPA: eicosapentaenoic acid; FA: fatty acid; FAME: Fatty acid methyl ester; GC: gas-liquid chromatography; GoF: Gulf of Finland HPLC: high-performance liquid chromatography; HUFA: highly unsaturated fatty acid; ICES: international council for the exploration of the sea; MANOVA: multi-way analysis of variance; MUFA: monounsaturated fatty acid; PC: principal component; PCA: principal component analysis; PUFA: polyunsaturated fatty acid; SFA: saturated fatty acid; SIMCA: soft independent modelling of class analogy; TCA: tricarboxylic acid.

\section{Authors' contributions}

MK and PJV conceived the study. TM and JP conducted the sampling and TR fatty acid analysis. PJV and RK performed the statistical calculations and prepared the graphics. All the authors contributed to data interpretation. MK wrote the manuscript with significant input from all the coauthors. All authors read and approved the final manuscript.

\section{Author details}

${ }^{1}$ Natural Resources Institute Finland (Luke), Management and Production of Renewable Resources, P.O. Box 2, Fl-00791 Helsinki, Finland. ${ }^{2}$ Department of Biosciences, University of Helsinki, P.O. Box 65, Fl-00014, Helsinki, Finland.

${ }^{3}$ Finnish Food Safety Authority Evira, Mustialankatu 3, Fl-00790 Helsinki, Finland.

${ }^{4}$ Natural Resources Institute Finland (Luke), Management and Production of Renewable Resources, Itäinen Pitkäkatu 3, Fl-20520 Turku, Finland.

\section{Acknowledgements}

We thank all those who have in different stages of the study helped in sampling, handling or analysing the samples, Roy Siddall for revising the English and two anonymous reviewers, whose suggestions and comments considerably improved the manuscript. The research was partly funded by the Academy of Finland (Project DIOXMODE, No. 102557, in the Baltic Sea Research Programme BIREME).

\section{Competing interests}

The authors declare that they have no competing interests.

\section{Availability of data and materials}

The datasets generated and analysed during the current study are not publicly available due to copyright restrictions, but may be available from the corresponding author on reasonable request.

\section{Ethics approval and consent to participate}

The research involved no human subjects, human material or human data. Fish used in the study were taken from the commercial catches of professional fishermen, and thus were not subject to national legislation on animal experimentation.

\section{Funding}

The research was partly funded by the Academy of Finland (project DIOXMODE, No. 102557, in the Baltic Sea Research Programme BIREME).

Received: 28 September 2016 Accepted: 13 March 2017

Published online: 20 March 2017

\section{References}

1. Parrish CC. Essential fatty acids in aquatic food webs. In: Arts MT, Brett MT, Kainz MJ, editors. Lipids in aquatic ecosystems. Dordrecht: Springer; 2009. p. 309-26.

2. Ahlgren $G$, Vrede T, Goedkoop W. Fatty acid ratios in freshwater fish, zooplankton and zoobenthos — are there spesific optima? In: Arts MT, Brett MT, Kainz MJ, editors. Lipids in aquatic ecosystems. Dordrecht: Springer; 2009. p. 147-78.

3. Bell JG, Tocher D, MacDonald F, Sargent J. Effects of diets rich in linoleic $(18: 2 n-6)$ and a-linolenic (18:3n-3) acids on the growth, lipid class and fatty acid compositions and eicosanoid production in juvenile turbot (Scophthalmus maximus L.). Fish Physiol Biochem. 1994;13:105-18. 
4. Logue JA, Howell BR, Bell JG, Cossins AR. Dietary n-3 long-chain polyunsaturated fatty acid deprivation, tissue lipid composition, ex vivo prostaglandin production, and stress tolerance in juvenile dover sole (Solea solea L.). Lipids. 2000;35:745-55.

5. Østbye TK, Kjær MA, Rørå AMB, Torstensen B, Ruyter B. High n-3 HUFA levels in the diet of Atlantic salmon affect muscle and mitochondrial membrane lipids and their susceptibility to oxidative stress. Aquac Nutr. 2011;17:177-90.

6. Spector AA. Lipid metabolism: essential fatty acids. In: Stipanuk MH, editor. Biochemical and physiological aspects of human nutrition. Philadelphia: Saunders/Elsevier; 2000. p. 365-83.

7. Tacon AGJ. Lipid nutritional pathology in farmed fish. Arch Anim Nutr. 1996;49:33-9.

8. Lukienko PI, Mel'nichenko NG, Zverinskii IV, Zabrodskaya SV. Antioxidant properties of thiamine. Bull Exp Biol Med. 2000;130:874-6.

9. Gibson GE, Zhang H. Interactions of oxidative stress with thiamine homeostasis promote neurodegeneration. Neurochem Int. 2002;40:493-504.

10. Bengtsson B-E, Hill C, Bergman Å, Brandt I, Johansson N, Magnhagen $C$, et al. Reproductive disturbances in Baltic fish: a synopsis of the FiRe project. Ambio. 1999;28:2-8.

11. Balon EK. Terminology of intervals in fish development. J Fish Res Board Can. 1975;32:1663-70

12. Vuorinen PJ, Keinänen M. Environmental toxicants and thiamine in connection with the M74 syndrome in Baltic salmon (Salmo salar). TemaNord. 1999;530:25-37.

13. Amcoff $P$, Börjeson $H$, Landergren $P$, Vallin L, Norrgren L. Thiamine (vitamin $\mathrm{B}_{1}$ ) concentrations in salmon (Salmo salar), brown trout (Salmo trutta) and cod (Gadus morhua) from the Baltic sea. Ambio. 1999;28:48-54.

14. Lundström J, Carney B, Amcoff P, Pettersson A, Börjeson H, Förlin L, et al. Antioxidative systems, detoxifying enzymes and thiamine levels in Baltic salmon (Salmo salar) that develop M74. Ambio. 1999;28:24-9.

15. Pickova J, Kiessling A, Pettersson A, Dutta PC. Comparison of fatty acid composition and astaxanthin content in healthy and by M74 affected salmon eggs from three Swedish river stocks. Comp Biochem Physiol B. 1998;120:265-71

16. Karlsson L, Ikonen E, Mitans A, Hansson S. The diet of salmon (Salmo salar) in the Baltic sea and connections with the M74 syndrome. Ambio. 1999;28:37-42.

17. Mikkonen J, Keinänen $\mathrm{M}$, Casini $\mathrm{M}$, Pönni J, Vuorinen PJ. Relationships between fish stock changes in the Baltic Sea and the M74 syndrome, a reproductive disorder of Atlantic salmon (Salmo salar). ICES J Mar Sci. 2011;68:2134-44.

18. Keinänen M, Uddström A, Mikkonen J, Casini M, Pönni J, Myllylä T, et al. The thiamine deficiency syndrome M74, a reproductive disorder of Atlantic salmon (Salmo salar) feeding in the Baltic Sea, is related to the fat and thiamine content of prey fish. ICES J Mar Sci. 2012;69:516-28.

19. Hansson S, Karlsson L, Ikonen E, Christensen O, Mitans A, Uzars D, et al. Stomach analyses of Baltic salmon from 1959-1962 and 1994-1997: possible relations between diet and yolk-sac-fry mortality (M74). J Fish Biol. 2001;58:1730-45.

20. Salminen M, Erkamo E, Salmi J. Diet of post-smolt and one-seawinter Atlantic salmon in the Bothnian Sea, northern Baltic. J Fish Biol. 2001;58:16-35.

21. Vuorinen PJ, Kiviranta H, Koistinen J, Pöyhönen O, Ikonen E, Keinänen M. Organohalogen concentrations and feeding status in Atlantic salmon (Salmo salar L.) of the Baltic Sea during the spawning run. Sci Total Environ. 2014:468-469:449-56.

22. Ojaveer E, Kalejs M. Ecology and long-term forecasting of sprat (Sprattus sprattus balticus) stock in the Baltic Sea: a review. Rev Fish Biol Fish. 2010;20:203-17.

23. Aro E. A review of fish migration patterns in the Baltic. Rapp P-v Réun Cons Int Explor Mer. 1989;190:72-96.

24. ICES. Report of the Baltic fisheries assessment working group (WGBFAS). ICES Document CM 2015/ACOM:10. 2015; $819 \mathrm{p}$.

25. Salminen M, Kuikka S, Erkamo E. Divergence in feeding migration of Baltic salmon (Salmo salar L.); the significance of smolt size. Nordic J Freshw Res. 1994:69:32-42.

26. Keinänen $\mathrm{M}$, Tolonen $\mathrm{T}$, Ikonen $\mathrm{E}$, Parmanne R, Tigerstedt C, Rytilahti J et al. Reproduction disorder of Baltic salmon-M74. Riista-ja kalatalouden tutkimuslaitos, Kalatutkimuksia_Fiskundersökningar. 2000;165: 38 p. (In Finnish with English abstract).
27. RKTL. Commercial marine fishery 2013. Official Statistics of Finland-Agriculture, Forestry and Fishery. 2014;Tilastoja 3/2014: 61 p.

28. ICES. Report of the Baltic salmon and trout assessment working group (WGBAST). ICES Document CM 2016/ACOM:09. 2016; 262 p.

29. Keinänen M, Uddström A, Mikkonen J, Rytilahti J, Juntunen E-P, Nikonen $S$ et al. The M74 syndrome of Baltic salmon: the monitoring results from Finnish rivers up until 2007. Riista-ja kalatalous_-Selvityksiä. 2008;4/2008: 21 p. (In Finnish with English abstract)

30. Keinänen M, livari J, Juntunen E-P, Kannel R, Heinimaa P, Nikonen S et al. Thiamine deficiency M74 of salmon can be prevented. Riista-ja kalatalous_-Tutkimuksia ja selvityksiä. 2014;14/2014: 41 p. (In Finnish with English abstract).

31. Alvarez MJ, Lopez-Bote CJ, Diez A, Corraze G, Arzel J, Dias J, et al. Dietary fish oil and digestible protein modify susceptibility to lipid peroxidation in the muscle of rainbow trout (Oncorhynchus mykiss) and sea bass (Dicentrarchus labrax). Br J Nutr. 1998;80:281-9.

32. Budge SM, Penney SN, Lall SP. Response of tissue lipids to diet variation in Atlantic salmon (Salmo salar): implications for estimating diets with fatty acid analysis. J Exp Mar Biol Ecol. 2011;409:267-74.

33. Skilbrei OT, Normann E, Meier S, Olsen RE. Use of fatty acid profiles to monitor the escape history of farmed Atlantic salmon. Aquac Environ Interact. 2015;7:1-13.

34. Iverson SJ, Field C, Bowen WD, Blanchard W. Quantitative fatty acid signature analysis: a new method of estimating predator diets. Ecol Monogr. 2004;74:211-35.

35. Røjbek MC, Tomkiewicz J, Jacobsen C, Støttrup JG. Forage fish quality: seasonal lipid dynamics of herring (Clupea harengus L.) and sprat (Sprattus sprattus L.) in the Baltic Sea. ICES J Mar Sci. 2014;71:56-71.

36. Linko RR, Kaitaranta JK, Vuorela R. Comparison of the fatty acids in Baltic herring and available plankton feed. Comp Biochem Physiol B. 1985;82:699-705.

37. Aro T, Tahvonen R, Mattila T, Nurmi J, Sivonen T, Kallio H. Effects of season and processing on oil content and fatty acids of Baltic herring (Clupea harengus membras). J Agric Food Chem. 2000;48:6085-93.

38. Szlinder-Richert J, Usydus Z, Wyszynski M, Adamczyk M. Variation in fat content and fatty-acid composition of the Baltic herring Clupea harengus membras. J Fish Biol. 2010;77:585-99.

39. Usydus Z, Szlifder-Richert J, Adamczyk M. Variations in proximate composition and fatty acid profiles of Baltic sprat (Sprattus sprattus balticus). Food Chem. 2012:130:97-103.

40. Slotte A. Differential utilization of energy during wintering and spawning migration in Norwegian spring-spawning herring. J Fish Biol. 1999;54:338-55.

41. Vuorinen PJ, Parmanne R, Vartiainen T, Keinänen M, Kiviranta H, Kotovuori $\mathrm{O}$, et al. PCDD, PCDF, PCB and thiamine in Baltic herring (Clupea harengus L.) and sprat [Sprattus sprattus (L.)] as a background to the M74 syndrome of Baltic salmon (Salmo salar L.). ICES J Mar Sci. 2002;59:480-96.

42. Vuorinen PJ, Keinänen M, Kiviranta H, Koistinen J, Kiljunen M, Myllylä T, et al. Biomagnification of organohalogens in Atlantic salmon (Salmo salar) from its main prey species in three areas of the Baltic Sea. Sci Total Environ. 2012:421-422:129-43.

43. ICES. Report of the Baltic fisheries assessment working group (WGBFAS). ICES Document ICES CM 2016/ACOM:11. 2016;793 p.

44. Richter H, McDermott JG. The staining of fish otoliths for age determination. J Fish Biol. 1990:36:773-9.

45. Kiviranta H, Ovaskainen ML, Vartiainen T. Market basket study on dietary intake of PCDD/Fs, PCBs, and PBDEs in Finland. Environ Int. 2004;30:923-32.

46. ISO. Cheese and processed cheese products - determination of fat content — gravimetric method (Reference method). ISO 1735:2004/IDF 5:2004; 16 p.

47. Slover HT, Lanza E. Quantitative analysis of food fatty acids by capillary gas chromatography. J Am Oil Chem Soc. 1979;56:933-43.

48. Tocher DR. Metabolism and functions of lipids and fatty acids in teleost fish. Rev Fish Sci. 2003;11:107-84.

49. Dalsgaard J, St. John M, Kattner G, Müller-Navarra D, Hagen W. Fatty acid trophic markers in the pelagic marine environment. Adv Mar Biol. 2003:46:225-340.

50. Warton $\mathrm{DI}$, Hui FKC. The arcsine is asinine: the analysis of proportions in ecology. Ecology. 2011;92:3-10. 
51. Kvalheim OM, Karstang TV. A general-purpose program for multivariate data-analysis. Chemom Intell Lab. 1987;2:235-7.

52. Wold S, Sjöström M. SIMCA: a method for analyzing chemical data in terms of similarity and analogy. In: Kowalski B, editor. Chemometrics: theory and application. Washington, DC: American Chemical Society; 1977. p. 243-82.

53. SAS Institute Inc. SAS/STAT 9.2 user's guide. Cary: SAS Institute Inc; 2008

54. Budge SM, Iverson SJ, Bowen WD, Ackman RG. Among- and within-species variability in fatty acid signatures of marine fish and invertebrates on the Scotian Shelf, Georges Bank, and southern Gulf of St. Lawrence. Can J Fish Aquat Sci. 2002;59:886-98.

55. Möllmann C, Kornilovs G, Fetter M, Köster FW. Feeding ecology of central Baltic Sea herring and sprat. J Fish Biol. 2004;65:1563-81.

56. Hardy R, Mackie P. Seasonal variation in some of the lipid components of sprats (Sprattus sprattus). J Sci Food Agric. 1969;20:193-8.

57. Sargent J, Tocher DR, Bell JG. The lipids. In: Halver JE, Hardy RW, editors. Fish nutrition. San Diego: Academic Press; 2002. p. 181-257.

58. HELCOM. Atlas of the Baltic Sea. Helsinki: HELCOM; 2010.

59. Casini M, Cardinale M, Arrhenius F. Feeding preferences of herring (Clupea harengus) and sprat (Sprattus sprattus) in the southern Baltic Sea. ICES J Mar Sci. 2004;61:1267-77.

60. Möllmann C, Kornilovs G, Fetter M, Köster FW. Climate, zooplankton, and pelagic fish growth in the central Baltic Sea. ICES J Mar Sci. 2005;62:1270-80.

61. Rönkkönen S, Ojaveer E, Raid T, Viitasalo M. Long-term changes in Baltic herring (Clupea harengus membras) growth in the Gulf of Finland. Can J Fish Aquat Sci. 2004;61:219-29.

62. Arrhenius F, Hansson S. Food consumption of larval, young and adult herring and sprat in the Baltic Sea. Mar Ecol Prog Ser. 1993;96:125-37.
63. Huovila T. Temporal changes and spatial differences in the food web of Baltic herring (Clupea harengus membras) indicated by fatty acid profile 2012; 59 p. Master thesis. University of Helsinki, Faculty of Biosciences, Department of Physiology and Neuroscience.

64. Casini M, Cardinale M, Hjelm J. Inter-annual variation in herring, Clupea harengus, and sprat, Sprattus sprattus, condition in the central Baltic Sea: what gives the tune? Oikos. 2006;112:638-50.

65. Peltonen H, Vinni M, Lappalainen A, Pönni J. Spatial feeding patterns of herring (Clupea harengus L.), sprat (Sprattus sprattus L.), and the threespined stickleback (Gasterosteus aculeatus L.) in the Gulf of Finland, Baltic Sea. ICES J Mar Sci. 2004:61:966-71.

66. Jensen KN, Jacobsen C, Nielsen HH. Fatty acid composition of herring (Clupea harengus L.): influence of time and place of catch on n-3 PUFA content. J Sci Food Agric. 2007;87:710-8.

67. Corraze G, Kaushik S. Lipids from marine and freshwater fish, Les lipides des poissons marins et d'eau douce. OCL. 1999;6:111-5.

68. Karlsson L, Karlström Ö. The Baltic salmon (Salmo salar L.): its history, present situation and future. Dana. 1994;10:61-85.

69. Pickova J, Dutta PC, Pettersson A, Froyland L, Kiessling A. Eggs of Baltic salmon displaying M74, yolk sac mortality syndrome have elevated levels of cholesterol oxides and the fatty acid 22:6 n-3. Aquaculture. 2003;227:63-75.

70. Torniainen J, Vuorinen PJ, Jones RI, Keinänen M, Palm S, Vuori KAM, et al. Migratory connectivity of two Baltic Sea salmon populations: retrospective analysis using stable isotopes of scales. ICES J Mar Sci. 2014;71:336-44.

\section{Submit your next manuscript to BioMed Central and we will help you at every step:}

- We accept pre-submission inquiries

- Our selector tool helps you to find the most relevant journal

- We provide round the clock customer support

- Convenient online submission

- Thorough peer review

- Inclusion in PubMed and all major indexing services

- Maximum visibility for your research

Submit your manuscript at www.biomedcentral com/submit 